\title{
A Tea Party Online: A Content Analysis of Local, Regional, and State Tea Party Websites
}

\section{Virgil Ian Stanford, George Mason University, USA}

\begin{abstract}
Since 2009, the Tea Party has played a prominent role in American politics, influencing both election outcomes and policymaking. Scholars and political pundits often argue about whether the movement constitutes an authentic economic populist movement within American conservatism or simply is a rebranding of classic conservative politics in the age of President Obama. Much can be discerned about the true nature of an organization by examining its public communications, particularly its online communications. This study analyzes the content of a stratified random sample of 50 local, regional, and state Tea Party websites to assess the true ideology of the political movement and the degree to which that ideology is consistent across the local nodes of this national political movement. The study finds that while economic issues are an important unifying principle among local Tea Party groups, that traditional conservative political causes such as opposition to President Obama, protecting Christian values, and cracking down on illegal immigrants also play a prominent role in Tea Party communications. Additionally, there is little cohesion that exists between the messaging of the local organizations due to the lack of centralized message control in the national Tea Party.
\end{abstract}

Keywords: Tea Party, American politics, political communication, websites, content analysis 
In 2009, a conservative political movement called the Tea Party began to play a prominent role in American politics and elections. Beginning as primarily a protest movement, by 2010 the Tea Party was influencing the selection of Republican congressional candidates, and the enthusiasm surrounding this conservative movement is partially credited with putting the Republicans in control of the House of Representatives (Srikrishnan, Pliner, Schlesinger, Goldstein, \& Khan, 2010). By the middle of 2011, the sixty-member House Tea Party Caucus had been at the center of numerous public policy debates (Cillizza\& Blake, 2011).

Following the Tea Party's rise to prominence, scholars began trying to explain the movement's popularity and define the true extent of its power. Some lauded the Tea Party as an authentic, populist outgrowth of American economic frustration (Rasmussen \& Schoen, 2010; Harris, 2010; Etzioni, 2011) while others questioned the movement's authenticity either strongly, claiming it was an Astroturf campaign designed and funded by Republican strategists to put pressure on the new administration (Krugman, 2009), or weakly,accusing it of being a simple rebranding of classic conservative ideology and beliefs (Williamson, Skopol, \& Coggin, 2011; Ashbee, 2011). Clearly, some evidence exists to support all three propositions, and the debate continues in both political and academic circles. What is certain is that scholars continue to research the Tea Party in order to better understand the nature of the organization and its beliefs.

A central characteristic of any social movement is a shared ideology or belief system, and much of this ideology can be gleaned from analyzing the movement's various forms of communication. Previous research on the communication of the Tea Party has focused primarily on signs at political rallies and the tweets of Tea Party political candidates, but little has been done to analyze Tea Party websites. Websites have become an important and ubiquitous feature of a modern organization's public communication effort. Previous studies of political campaign and environmental activist websites have revealed information about how organizations communicate online and what issues are most important to them. Though it is essential to recognize the strategic nature of these communication efforts, examining the messages on an organization's website gives at least an indication of that organization's beliefs, as it were, straight from the horse's mouth. 
This study examines local and regional Tea Party websites from all 50 states in order determine what beliefs and ideologies are at the core of the movement. This type of analysis is important because the decentralized organizational structure, identified by Williamson, Skopol, \& Coggin (2011), makes devising and distributing a uniform message all the more difficult. The goal of this study is twofold. First, the study hopes to illuminate the extent to which the local Tea Party organizations coalesce around an economic message, suggested by some scholars, or other conservative political messages, primarily a dislike of President Obama, suggested by others. Second, the study will evaluate the degree to which Tea Party websites, taken together, advocate for a coherent public policy platform and whether that platform is indicative of a populist economic movement or a rebranding of the same conservative policy platform that existed before the Tea Party came into being.

\section{Literature Review}

The explanations for the existence of the Tea Party as a political movement vary widely. Several scholars and authors have argued that the Tea Party is an unprecedented form of rightwing, economic populism fueled by a sudden realization of the poor economic condition of the United States and the inability of political elites to address problems such as the size of government, entitlement spending, and structural deficits (Rasmussen \& Schoen, 2010; Harris, 2010; Etzioni, 2011). Meanwhile, others have presented evidence that the Tea Party is simply a rebranding of classic Republican conservatism with an attempt to distance the movement from the Republican Party because of perceived ideological and policy failures of the Bush Administration (Williamson, Skopol, \& Coggin, 2011; Ashbee, 2011). For example, Tea Party demographics tend to be older, white, and male, the main demographics of Republican voters. Additionally, a majority of Tea Party members vote Republican, and a substantial plurality have worked for or donated money to Republican candidates (Williams et al., 2011). Still, others have suggested that the Tea Party coalesced around racist and nativist feelings stirred by the election of President Obama and that the focus on economic policy is possibly a cover for a more radical agenda on immigration and race issues (Walker, 2011; Enck-Wanzer, 2011; Street \& DiMaggio, 2011).

Many studies have tried to uncover the true nature of the Tea Party's raison d'être. These studies have used a wide variety of research methodologies including personal interviews, analysis of public opinion survey data, and various forms of content analysis, but the ultimate 
purpose of all these studies is to uncover a core ideology that constitutes the foundation of this political movement. Ideology is a key component of social and political movements. Olivier and Johnston (2000) define ideology as "a system of meaning that couples assertions and theories about the nature of social life with values and norms relevant to promoting or resisting social change" (p. 43). One way to observe elements of ideology or culture is to examine linguistic tools and communications employed by an organization. While these communications exist at the level of artifacts rather than espoused values or basic assumptions and do not constitute the full extent of the organization's ideology or culture, an organization's communication efforts can provide a starting point for identifying and assessing key beliefs that contribute to forming a complete belief system (Schein, 1997).

In order to better understand the nature of the Tea Party movement, a number of scholars have evaluated various communication efforts put forward by the Tea Party or by the news media covering the group. Previous studies of the theory behind the growth of social movements have noted the importance of communications for framing the positions of the organization, attracting membership, and securing the attention of political elites, namely journalist and politicians (Olivier \& Johnston, 2000). Scholars have produced qualitative examinations of signs held by Tea Party members at public rallies depicting racist imagery (Schrader, 2011), studies of the ideological consistency of online tweets of Tea Party supported candidates in the 2010 midterm elections (Livne, Simmons, Adar, \& Adamic, 2011), and a comparison of the amount of cable news coverage on FNC and CNN of the Tea Party throughout its first year (Williamson, Skopol, \& Coggin, 2011). Yet, few if any studies have examined the content of local Tea Party websites.

\section{Website Content Analysis}

Website content analysis has become an important technique for examining social movements and political organizations. As early as 2001, Best and Kellner studied how the Zapatista movement in Mexico used the Internet to recruit members, activate supporters, and mobilize political action (Kahn \& Kellner, 2004). More recently, the anti-Iraq-war movement in the United States and the recent Arab Spring pro-democracy movements in the Middle East used the Internet both as an expressive and organizing medium. A fairly extensive body of literature has developed analyzing how environmental activists use the Internet and their websites to communicate their views, supplement classic organizational functions, and 
mobilize publics for more traditional forms of social and political engagement (see Bennett 2003; McCaughey \& Ayers, 2003;Reber, 2006; Stein, 2009). Salter (2003) conceptualizes the Internet as a new Habermassian public sphere, a place where people can share ideas about society with people halfway across the world and new social movements can coalesce around those ideas. This theory clearly presupposes that websites can communicate a substantial amount about the core beliefs of an organization and how that organization sees itself and its role in the political landscape. Thus, examining the content and messages projected by Tea Party websites can reveal important information about the organization's beliefs.

The difficulty is in deciding what element of the Tea Party web sphere ought to be examined. The Tea Party has a unique organizational structure that makes it difficult to effectively examine. Williams et al. (2011) explain that the Tea Party has a decentralized organizational structure that can be thought of as containing three distinct parts. Funding is provided at the top by a group of politically well connected, conservative advocacy organizations such as FreedomWorks and Americans for Prosperity. These groups fund the national Tea Party organizations such as the Tea Party Express or Tea Party Patriots that act as the national face of the organization. Second, a network of conservative media organizations, including the Fox News Channel and conservative radio hosts like Rush Limbaugh and Glenn Beck, provide constant media attention and national publicity. Fox News even sponsored the first set of "Tax Day Tea Party" rallies and publicized them throughout their news and opinion content. The final part of the organization involves local Tea Party groups that recruit members and organize events throughout the year. These local organizations have direct contact with members and provide the actual "grassroots" part of the movement. With little direct guidance from the national organizations and media communications, these groups are likely to craft their own messages, tailored specifically to their own membership. For this reason, examining the websites of these groups should provide significant information about what Tea Party members actually believe.

\section{Message Cohesion}

The concept of cohesion features prominently in two strands of political science literature. First, there is a concept called "party cohesion" that attempts to assess the strength of a political party by measuring the similarity of party members' votes (seeNorpoth, 1976; Hix, Noury, and Roland, 2005; Gianetti and Laver, 2005; Rahat, 2007). A cohesive party, as 
opposed to a factionalized party, is better able to control the legislative agenda, implement their platform, and communicate their views to the public at large. For parties, cohesion occurs around a particular ideology, which can simply be defined as a set of core principles. Thus, when a party votes cohesively on a particular issue such as abortion, gun control, or tax reductions, they are essentially communicating to the public the message that this stance is a core belief of their party.

Moreover, cohesion plays a central role in the Narrative Policy Framework (NPF) (Shanahan, Jones, and McBeth, 2011). The NPF focuses on the importance of policy narratives in explaining the public policy process. "Stakeholders use words, images, and symbols to strategically craft policy narratives to resonate with the public, relevant stakeholders, and governmental decision makers, with the aim of producing a winning coalition" (p. 536). Shanahan et al. also point out that though these coalitions share an ultimate policy goal, they are made up of many individual entities, each with their own prioritization of beliefs. For example, one member of a gun control coalition may prioritize background checks while another my favor banning assault weapons. Though they both favor stricter gun laws and may even work together, as their proposals aren't mutually exclusive, their narrative is still likely to be more disjointed than if they were both promoting the same gun control measure, either background checks or an assault weapons ban.

Cohesion is an essential element of the communication of any political group or movement. An organization is defined by its core beliefs. When those beliefs are communicated publicly in a cohesive and uniform manner, actors outside the organization (politicians, the media, and the public) have little trouble identifying the objective of the movement. On the other hand, a disjointed message structure with different parts of the organization identifying different, sometimes contradictory, goals and presenting an inconsistent narrative leaves political actors uncertain of what to make of the movement and can interfere with the movement's ability to achieve its political goals, such as occurred with the Occupy Wall Street movement (Chun, 2011).Though websites are only a portion of the public communication of an organization, assessing whether the different local and regional Tea Parties are producing messages that are cohesive around a single ideology or public policy outcome can reveal much about the strength of the movement as a whole. 


\section{Research Questions}

If the Tea Party movement is an authentic grassroots political movement unified behind a platform of libertarian or conservative economic populism, their websites could be expected to be dominated by economic messages, such as decreasing overall federal spending, decreasing the budget deficit, removing unnecessary regulation of businesses, etc... In contrast, if the Tea Party is simply a rebranding of classic conservatives coalescing around one political objective, opposition to Barack Obama, the economic objectives would take a back seat to criticisms of the president and discussions of his failures.

Additionally, the core beliefs of the Tea Party have implications for public policy. Social and political movements are often oriented toward producing social and political change. For the Tea Party, the change members purport to desire is in the realm of economic policy. One would suspect that the bulk of policy reforms advocated by such an organization would be economic policy changes. Meanwhile, if the organization is just a rebranding of classic conservatism, one would expect to see a less unified policy platform more consistent with conservative positions on a variety of economic, political, and social issues such as abortion, gay marriage, gun rights, and military expansion, just to name a few.

Finally, affiliates of a single social or political movement would be expected to exhibit highly similar messaging communicating their core principles and policy agenda. While a small amount of local variation could be anticipated, an organization demonstrating a cohesive messaging strategy would have a high degree of similarity in the topics and themes presented in its online communication. Meanwhile, an organization whose affiliates are only weakly connected would be expected to demonstrate less message cohesion, with topics varying widely from website-to-website. An organization's level of message cohesion does have substantial implications for its success in attracting members and succeeding in its policy objectives, as illustrated by the literature on policy narratives and party cohesion. This truth is reflected in the mantra from the field of political communication and public relations to "stay on message."

With the previous research on the Tea Party and social movements in mind, this study proposes the following three research questions: 
RQ1: What types of themes and topics do Tea Party websites use to support their political positions?

RQ2: Do the public policies advocated or opposed on Tea Party websites constitute a unified economic policy platform?

RQ3: What is the level of message cohesion between local Tea Party Websites?

\section{Methodology}

\section{Data and Sampling}

This study used a random sampling procedure, stratified by state, to select a sample of 50 local, regional, or state Tea Party websites. As a sampling frame, the national Tea Part Patriots website (http://www.teapartypatriots.org/) provided links to local Tea Party groups in every state in the United States. Although this is not a comprehensive list of all Tea Party websites in the Tea Party web sphere, the list is large containing more than 1000 individual Tea Party affiliated groups and there is no immediate reason to think that websites listed on the Tea Party Patriots national website differ systematically from Tea Party websites in general. The website divides the list of local organizations by state. For each state, a random number was generated based on the total number of local organizations in the state. If the number generated corresponded to an organization with no website link or a broken link, the organization immediately below in the list was selected until a codable website was found.

\section{Coding}

In order to ascertain the full breadth of themes present on Tea Party websites, this study employed a two-stage coding process. A sample of 50 randomly selected websites was coded using an open coding technique, commonly used in survey research to handle open-ended questions, where all individual themes and topics present on the websites were initially counted and coded, and then the scheme was further refined by recoding the topics into broader, mutually exclusive groups. Topics were coded using a binary coding scheme with " 1 " indicating the topic was present on the website and " 0 " indicating the topic's absence. The first stage resulted in 70 individual topics under five general themes: general political issues, political figures, national policy-specific issues, state or local policy-specific issues, and other topics. The list of topics was then further consolidated based on two criteria. First, some of the categories that contained related topics were consolidated to form even larger, mutually exclusive categories. For example, the topics "War on Christmas," "Christian 
Values," "Pro-life," “Oppose Gay Marriage," and "Oppose Islam/Sharia Law" were consolidated to form one large topic called "Religion." Second, all topics with a frequency of 4 percent or under ( 2 websites in 50) were dropped from the coding scheme.

\section{Results}

\section{Data Analysis}

The final coding scheme contained 27 individual topics under the original five themes. Preliminary data analysis revealed the most common topics, those above 20 percent frequency, present on Tea Party websites as shown in Table 1. Fifty-four (54) percent of the Tea Party websites contained some mention of "Fiscal Responsibility" and "Limited Government" as goals of the organization. In fact, many if not most of the websites included the organizational objectives "Fiscal Responsibility, Limited Government, and Free Markets," usually immediately under the top banner of the website. This reveals an interesting amount of message consistency for an organization with such a decentralized structure. Still, "Free Markets" fell slightly behind the other two topics with a mention in 44 percent of the website sample.

Table 1: Most Common Topics on Local, Regional, and State Tea Party Websites

\begin{tabular}{l|c}
\hline Content Topic/Theme & Percentage of Websites with Theme Present \\
\hline Fiscal Responsibility & 54 \\
Limited Government & 54 \\
Defend the Constitution & 48 \\
Obama & 46 \\
Free Markets & 44 \\
Congress/Congressperson & 28 \\
is the Problem & \\
Republican Primary & 26 \\
Coverage & \\
Repeal Healthcare & 22 \\
Reform & \\
Religion & 20 \\
\hline
\end{tabular}


The next most common topics were "Defend the Constitution/Founding Fathers" and "President Obama" mentioned in 48 and 46 percent of the websites respectively. It comes as little surprise that mentions of the Constitution and the Founding Fathers would be common on Tea Party websites given their fetishizing of American history (Lepore, 2010). Similarly, criticisms of President Obama were not unexpected. Initially, criticisms of President Obama were coded in eight different categories (see Table 2 below), but during the second round of coding, they were consolidated into a single category. Table 2 shows a large variability in the types of attacks leveled at the president. The most common type was electoral with 16 percent of the websites trying to galvanize support for defeating President Obama in the 2012 election. Still, several other Obama-based topics reflected the common media stereotype of the Tea Party with accusations that the president is a socialist ( 8 percent) and questions about his citizenship (4 percent). Regardless of the form of the argument, it is clear that opposition to President Obama is a core element of the Tea Party organization's message.

Table 2: Mentions of President Obama on Tea Party Websites

\begin{tabular}{l|c}
\hline Topic/Theme & Percentage of Websites with Theme Present \\
\hline Defeat Obama in the Election & 16 \\
Obama is Corrupt & 10 \\
Obama is a Socialist & 8 \\
Obama made Economy Worse & 8 \\
Obama Helps America's Enemies & 4 \\
Obama Supports Unions & 4 \\
Obama is not a Citizen & 4 \\
Obama is a Despot & 2 \\
Total Obama-based Topics & $46^{*}$ \\
\hline
\end{tabular}

*Not a sum of the individual types of arguments because several websites contained multiple Obama-based arguments.

Further mentions of specific political figures took the form of either criticisms of current congressmen (28 percent) or mentions of Republican presidential primary candidates (26 percent). The only policy-specific message to receive mention in 20 percent of the Tea Party websites was repealing President Obama's healthcare reform law (22 percent). It could be argued that this policy issue serves as a proxy for anger directed at President Obama, being 
the signature policy effort of his administration, but this opposition could also be fueled by the limited government ideology of many Tea Party groups, so this conclusion would be difficult to definitively draw. Despite specific claims that the Tea Party represents an evolution beyond classic Christian conservatism's focus on religious values, Religion still evidently plays a significant role in at least a significant subset of Tea Party organizations. Religious issues were mentioned in 20 percent of the website sample.

While only one policy-specific topic was mentioned in more than 20 percent of Tea Party websites, it's important to examine the full range of policy-specific topics in order to test the validity of the common argument that the Tea Party has a primarily economic policy agenda and has coalesced around economic issues. Of 24 national policy-specific arguments found on Tea Party websites (from the initial round of coding), eight, or one-third, had some relationship to economic policy. These included "Pass a Balanced Budget Amendment," "Audit or Abolish the Federal Reserve," "Pass the Ryan Budget," "Don't Raise the Debt Limit," "Create Trade Protection for American Goods," "Reform the Tax Code," "Repeal the Dodd-Frank Act" and "Pass the FATCA (Foreign Account Tax Compliance Act)." None of these economic policy topics were individually mentioned in more than 8 percent of the Tea Party websites. The three most common policy-specific topics in the sample were "Repeal Healthcare Reform (22 percent)," "Repeal Gun Control (14 percent)," and "Pass Immigration Reform (14 percent)." These three topics show little difference from a classic conservative social policy platform, lending credence to the argument that the Tea Party is basically a rebranding of conservatism rather than some new conservative economic populism. If all 8 economic policy topics are consolidated into one category called "Economic Policy," they still can only be found in 26 percent of the sampled websites. While economic policy is clearly important to the Tea Party, it appears that they do not have a solid, coherent economic policy platform.

To measure message cohesion, a number was computed indicating the similarity of each website to every other one. This number is a percentage calculated as a ratio of the number of shared topics $\left(S_{i}\right)$ over the total number of present topics including those that were shared $\left(S_{i}\right)$ and those that were different $\left(D_{i}\right)$. Then for each website in each state, the similarity percentage for each pair group of websites was summed and divided by the total number of pairings $(n-1=49)$ to create a measure of mean similarity, or cohesion, for each website 
indicating how similar that website is to each of the other ones. Thus, cohesion is represented by the following equation.

$$
\mathrm{C}=\frac{\sum\left(\mathrm{S}_{i} / \mathrm{S}_{i}\right.}{\left.\underline{\mathrm{N}} \underline{\mathrm{D}}_{i}\right)}
$$

The descriptive statistics for the entire sample can be found in Table 3. Cohesion scores range from 0.31 to 0.03 with a mean of 0.18 . The website for the Williamsburg Historic Triangle Tea Party in Virginia was the most similar to the entire body of websites while the Guthrie Center Tea Party Movement in Iowa was the most different. Overall, message cohesion seems low. The mean of 0.18 indicates that the average Tea Party website only shares about 18 percent of the topics it covers with any other randomly selected Tea Party website. Put another way, one could expect a substantial amount of message variability between Tea Party websites, especially from different states.

Table 3: Descriptive Statistics for Message Cohesion

\begin{tabular}{l|l}
\hline Mean & 0.182147844 \\
Standard Deviation & 0.054012438 \\
Maximum & 0.310094384 \\
Minimum & 0.029952219 \\
\hline
\end{tabular}

\section{Discussion}

When it comes to answering Research Question 1, it is clear that there is a substantial amount of variability in the topics addressed on Tea Party websites. Only two topics "Fiscal Responsibility" and "Limited Government" were present on more than half of the websites that were analyzed. This variability is likely influenced by the decentralized organizational structure of the Tea Party. With no hierarchical message control strategies, the individual local organizations are free to communicate the issues important to them, whether federal, state, or local.

Meanwhile, it is also clear that opposition directed toward President Obama is also a significant piece of the ideology that draws members to the Tea Party and holds them together. Tea Party organizations often say that they are against both the Republican and Democratic Party establishments, but the websites evaluated in this study do not reflect much opposition at all toward mainstream conservatives or their policies. 
As for the Tea Party supporting a consistent public policy agenda across the many local organizations as asked in Research Question 2, it appears clear that they do not have a unified policy agenda. The policy initiatives supported vary greatly from group to group. Where economic policy is concerned, Tea Party groups desire a haphazard assortment of economic policies, some of which even contradict the ideals that many of these organizations favor. For instance, a policy of protectionism for American industry (promoted by a Tea Party group in Pennsylvania) contradicts the free market ideology claimed by 44 percent of Tea Party organizations.

The majority of policy initiatives discussed on Tea Party websites have little to do with the economy or fiscal responsibility. Instead, they represent an overall conservative policy agenda including issues like repealing gun control laws, restricting immigration, denying global warming, and repealing healthcare reform. From just the policy profile alone, it would be difficult to differentiate this body of websites from average conservative organizations. While the organizations may draw people who have never been involved in politics before(a common claim of the Tea Party), it is unlikely that the uniqueness of the Tea Party message is what causes people to join. This policy agenda points to the Tea Party as a rebranding of the conservative message in the age of Obama and the Great Recession.

It is also important to recognize that religion still plays an important role for Tea Party organizations, though it is a more subdued role than religion played for conservatives in the 1990s and early 2000s. Religious messages were mentioned on one-fifth of local Tea Party websites. Classic Christian social issues, such as abortion and gay marriage, are still a part of the belief system for some Tea Party groups. Additionally, many of the Tea Party groups that mention religion talk about it in the context of the United States being a nation established on Christian values and that this was the Founding Fathers' intent. Clearly, the role of religion in the Tea Party movement could be a vital area of future research.

Previous studies of Tea Party messages have found some evidence of both racism and nativism in the Tea Party's ideology. This study finds no evidence of racism on Tea Party websites. In fact, some groups went out of their way to post messages on their websites denouncing racism. As for nativism, it could be argued that the high priority given to 
immigration reform policy is a product of nativist tendencies. This idea concurs with Williamson et al. (2011) research, which found an intense desire among Massachusetts Tea Party members to limit illegal immigration and suggested this was a product of nativism because it was influenced by desires to prevent changes in the ethnic makeup of the country rather than practical concerns about following the law or taking American jobs. Still, the reason why immigration reform is so high on the list of mentioned policy initiatives remains a mystery as far as this study is concerned. Occasional other topics hint at nativism including support for a policy of trade protection and negative messages about Islam, but these two topics were rare in the entire body of websites.

Lastly regarding Research Question 3, there appears overall to be only a small amount of message cohesion between the local Tea Party groups when examining the entire body of Tea Party websites. The average Tea Party website is only likely to have about 18 percent of its content be the same as any other randomly selected website from the sample. The website most similar to the others came from the Williamsburg Historic Triangle Tea Party in Virginia and presented messages about "Fiscal Responsibility," "Limited Government," "Free Markets," "Defending the Constitution and Founding Fathers," "President Obama," and "Economic Policy." Still, this website was only 31 percent similar to the overall body of websites showing the great diversity of topics and themes contained in the Tea Party web sphere. This non-cohesive messaging likely results in political actors being unsure exactly what the Tea Party platform is and thus makes it difficult for the Tea Party to dominate the nation's political and policy agenda.

\section{Limitations}

This study has several significant limitations. First, it uses a convenient sample frame to find the websites for analysis, which makes no claim to represent the entire population of Tea Party websites. Still, this researcher has no reason to believe that websites linked to through the national Tea Party Patriots website have any systematic difference from the overall body of Tea Party websites. In fact, there was a worry that these websites would show a high level of sophistication due to the self-selection of linking from a national forum, but most of the websites showed a remarkable lack of sophistication in design, leading the researcher to believe they are probably indicative of the design and messaging of the average Tea Party website. 
Additionally, the fact that a study likes this had not been attempted before research began meant that a concrete coding scheme was difficult to devise prior to beginning the research. With no guideline to go by, this study attempted a more open and flexible coding scheme, a technique often used in coding open-ended questions in public opinion survey. This method clearly led to a number of judgment calls on the part of this researcher and resulted in several non-mutually exclusive categories, which necessitated a second round of coding. It is important to note that the coding process for this and future similar studies must continue to be refined.

Finally, some researchers will likely criticize the notion that a concept as theoretically complex as ideology can be revealed simply by identifying topics mentioned on an organization's website. This criticism is justified, but it is not the goal of this study to produce an ideological profile of the Tea Party. Instead, this study seeks to consider the information the average website visitor would get from the average Tea Party website and whether these messages match up to previous research on the Tea Party's ideology and form a coherent narrative about their beliefs and reason for existence. In this endeavor, this study represents only an important first step.

\section{Conclusion}

As the debate continues among politicians, academics, and journalists over the true nature and influence of the Tea Party as a force in American politics, this study finds evidence that lends credence to the notion that the Tea Party is closer to a rebranding of classic conservative principles than a never-before-seen political movement harnessing populist outrage on the right. It will also be difficult to argue going forward that they only care about the economy. As suggested by previous research, opposition to President Obama is almost as important as the principles of fiscal responsibility or limited government. Finally, this study shows that an attempt by politicians to determine a clear public policy platform from the Tea Party is a difficult if not impossible task. Individual Tea Party organizations appear to support or oppose a wide variety of policy initiatives with little consistency from group to group. This fact appears to be the first concrete limitation of the Tea Party's decentralized organizational structure. 


\section{References}

Ashbee, E. (2011). Bewitched - the tea party movement: Ideas, interests, and institutions. The Political Quarterly , 82 (2), 157 - 164.

Bennet, W. L. (2003). Communicating global activism. Information, Communication, and Society , 6 (2), 143 - 168.

Chun, J. (2011). Occupy wall street's marketing problem: Can experts help solve their identity crisis. Huffington Post, http://www.huffingtonpost.com/2011/11/17/occupy-wall-streets-marketingproblem_n_1098422.html.

Cillizza, C., \& Blake, A. (2011, July 12). The tea party, the debt ceiling, and John Boehner's conundrum. Retrieved January 2012, from The Washington Post Online: http://www.washingtonpost.com/blogs/the-fix/post/the-tea-party- the- debtceiling-and-john-boehners-conundrum/2011/07/11/gIQAZMESAI_blog.html

Enck-Wanzer, D. (2011). Barack Obama, the tea party, and the threat of race: On racial neoliberalism and born again racism. Communication, Culture, \& Critique , 4 $23-30$.

Etzioni, A. (2011). The tea party is half right. Society , 48, 197 - 202.

Gianelli, G. \& Laver, M. (2005). Party cohesion, party factions, and legislative party discipline in Italy. Prepared for delivery at the 2005 Joint Workshop Sessions of the European Consortium for Political Research: Granada, Spain, April 13-19.

Harris, L. (2010, June \& July). The tea party vs. the intellectuals. Policy Review , 3 14.

Hix, S., Noury, A., \& Roland, G. (2005). Power to the parties: Cohesion and competition in European Parliament, 1979 - 2001. British Journal of Political Science, 35, 209 -234 .

Kahn, R., \& Kellner, D. (2004). New media and internet activism: From the battle in seattle to blogging. New Media and Society , 6 (1), 87 - 95.

Krugman, P. (2009, April 12). Tea parties forever. Retrieved August 2011, from New York Times Online: http://www.nytimes.com/2009/04/13/opinion/13krugman.html

Lepore, J. (2010). The whites of their eyes: The tea party's revolution and the battle over american history. Princeton, NJ: Princeton University Press. 
Livne, A., Simmons, M. P., Adar, E., \& Adamic, L. A. (2011). The party is over here: Structure and content in the 2010 election. The Fifth International Association for the Advancement of Artificial Intelligence Annual Conference.

McCaughey, M., \& Ayers, M. D. (2003). Cyberactivism: Online activism in theory and practice. New York: Routledge.

Norpoth, H. (1976). Explaining party cohesion in congress: The case of shared political attitudes. American Political Science Rview, 70 (4), 1156 - 1171.

Olivier, P. E., \& Johnston, H. (2000). What a good idea!: Ideologies and frames in social movement research. Mobilization , 4 (1), 37 - 54.

Rahat, G (2007). Determanents of party cohesion: Evidence from the case of the Israeli Parliament. Parliamentary Affairs, 62 (2), 279 - 296.

Rasmussen, S., \& Schoen, D. (2010). Mad as Hell: How the Tea Party Movement is Fundamentally Remaking Our Two-Party System. New York, New York: Harper Collins.

Reber, B. H. (2006). How Activist Groups Use Websites in Media Relations: Evaluating Online Press Rooms. Public Relations Research , 18 (4), 313 - 333.

Schein, E. H. (1997). Uncovering the levels of culture. In E. H. Schein, Organizational Culture and Leadership (pp. 16 - 27). Jossey-Bass Publishers.

Schrader, B. T. (2011). The Tea Party: The Discourse of Class, Race, and Gender/Sexuality. Retrieved from Colorado State University Doctoral Dissertations: http://gradworks.umi.com/14/92/1492430.html

Srikrishnan, M., Pliner, J., Schlesinger, J., Goldstein, J., \& Khan, H. (2010, Nov. 3). Which Tea Party Candidates Won? Retrieved November 2011, from ABC News Online: http://abcnews.go.com/Politics/2010_Elections/vote-2010- elections-tea-partywinners-losers/story?id=12023076\#.TzXpo11aDP8

Stein, L. (2009). Social movement web use in theory and practice: a content analysis of US movement websites. New Media and Society, 11 (4), 749 - 771.

Street, P., \& DiMaggio, A. (2011). Tea party racism. In P. Street, \& A. DiMaggio, Crashing the Tea Party: Mass Media and the Campaign to Remake American Politics (pp. 75 - 100). Boulder, CO: Paradigm.

Walker, C. E. (2011). "We're losing our country": Barack Obama, Race \& the Tea Party. Daedalus , 140 (1), 125 - 130. 
Williamson, V., Skopol, T., \& Coggin, J. (2011). The tea party and the remaking of american conservatism. Perspectives on Politics , 9 (1), 25 - 43. 


\section{Appendix A:}

In addition to calculating the raw percentages of various topics and the level of message cohesion between the different websites, this study also investigated whether there were any external, state-level factors that explained the presence of particular topics in certain states. A series of hypotheses were formulated about these potential relationships.

H1: Tea Party websites that present religious content will be in states with higher church attendance.

H2: Tea Party websites that discuss economic policy will represent states that have higher unemployment rates.

H3: Tea Party websites that are critical of President Obama will represent states that have higher unemployment rates.

H4: Tea Party websites that are critical of President Obama are more likely to be states where the president did not win the popular vote in 2008.

For the first three hypotheses, two group means comparison t-tests were run. Using data about the percentage of the state population that attends church on a weekly basis, obtained from Gallup polling (2009), the mean church attendance was compared between states where the Tea Party presented religious content and states where they did not present any religious content. Although states where the Tea Party websites had religious content also had a slightly higher percentage of their population attend church on a weekly basis (43.9 percent vs. 41.0 percent), t-tests revealed that this was not a statistically significant difference ( $\mathrm{p}=$ $0.19)$.

Additional means comparison of the unemployment rate also failed to achieve statistical significance. There was almost no difference in unemployment rates in states where the Tea Party websites mentioned econmic policy. States where Tea Party websites were critical of President Obama experienced slightly higher unemployment rates than states that did not mention the president ( 7.9 percent vs. 7.2 percent). 
Appendix Table 1: Results of Means Comparisons using Two Sample T-tests for Various Hypotheses

\begin{tabular}{|l|l|l|l|}
\hline $\begin{array}{l}\text { H1 (Church } \\
\text { Attendance) }\end{array}$ & Mean (Group 1) & Mean (Group 2) & P-Value \\
\hline $\begin{array}{l}\text { H2 (Unemployment } \\
\text { Rate) }\end{array}$ & $\begin{array}{l}7.66 \text { (no economic } \\
\text { policy) }\end{array}$ & $\begin{array}{l}7.25 \text { (economic } \\
\text { policy) }\end{array}$ & 0.4759 \\
\hline $\begin{array}{l}\text { H3 (Unemployment } \\
\text { Rate) }\end{array}$ & $\begin{array}{l}7.18 \text { (no Obama } \\
\text { mention) }\end{array}$ & $\begin{array}{l}7.96 \\
\text { mention) }\end{array}$ & 0.0727 \\
\hline
\end{tabular}

Finally, crosstabulations comparing states where Tea Party websites are critical of the president to states where the president also won the popular vote in 2008 also failed to reveal any type of significant relationship. In fact, the table below shows that in states where President Obama lost the popular vote, Tea Party websites were actually less likely to directly criticize him. It is still possible that some of these hypotheses would prove fruitful for future investigations. Unfortunately, it is likely that the lack of significant relationships between these factors was at least partly caused by the simplistic design of this study that only collected data on one website per state.

Appendix Table 2: Crosstabulation of Mentions of President Obama with State-level Vote in the 2008 Election

\begin{tabular}{l|l|l|l} 
& \multicolumn{2}{l|}{ obama mention } & \\
\hline obama_vote & no & yes & Total \\
\hline no & 13 & 9 & $\mathbf{2 2}$ \\
\hline yes & 14 & 14 & $\mathbf{2 8}$ \\
\hline Total & 27 & 23 & $\mathbf{5 0}$
\end{tabular}

